\title{
ПРОАКТИВНЫЕ ЛИЧНОСТНЫЕ РЕСУРСЫ У БОЛЬНЫХ С ОСТРЫМ НАРУШЕНИЕМ МОЗГОВОГО КРОВООБРАЩЕНИЯ, НАХОДЯЩИХСЯ НА ВОССТАНОВИТЕЛЬНОМ ЛЕЧЕНИИ
}

\begin{abstract}
Аннотация. В ходе исстедования изучены личностные особенности проактивного поведения у больных с острым нарушением мозгового кровообращения (ОНМК) по ишемическому типу. Установлено, что ведущими личностными предикторами, ответственными за формирование проактивных паттернов, у обследованных пациентов выступают соииально-детерминированные потребности (метапотребности) и свобода принятия рещений. Наименее развитыми компонентами проактивности у больных с ОНМК являются способность к рефлексии и прогнозу последствий своего поведения, что, вероятно, обусловлено снижением когнитивных процессов. Наиболее часто в обследованной выборке встречаются такие проактивные копинг-стратегии, как проактивное, рефлексивное и превентивное совладание. Проактивная агрессия как намеренное жестокое поведение у обследованных пациентов проявляется значительно реже, чем реактивная агрессия. В ходе исследования было установлено, проактивные компоненты личности, проявляющиеся в стремлении больных к достижению значимых иелей, могут быть использованы как личностный ресурс, влияющий на успешность восстановительной терапии.
\end{abstract}

Ключевые слова: проактивное поведение, проактивность, агрессия, совладающее поведение, ОНМК, инсульт, ресурсы личности, копинг-стратегии, реактивная агрессия, проактивная агрессия.

\section{Актуальность}

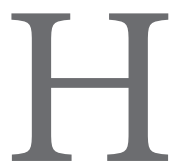

а сегодняшний день не утратившей свою актуальность стоит проблема взаимосвязи когнитивных и поведенческих нарушений, возникающих в результате острого нарушения мозгового кровообращения (ОНМК). Следует отметить, что в исследованиях последних лет ${ }^{1}$ акцент

\footnotetext{
1 Астаева А.В., Епанешникова Н.В. Нейропсихологическая характеристика нарушений речи при острых нарушениях мозгового кровообращения и проблемы их классификации в отечественной и зарубежной нейропсихологии // Вестник ЮжноУральского государственного университета. Серия: Психология. 2012. № 6 (265). С. 73-79; Бисерова С.В., Павлова В.С. Сопоставление когнитивных и психоэмоциональных изменений у лиц, перенёсших острое нарушение мозгового кровообращения // Вятский медицинский вестник. 2007. № 1. С. 46; Гайфутдинова Л.В., Васильева М.А. Факторы эффективности восстановления речи у больных, перенесших острое нарушение мозгового кровообращения и черепно-мозговую травму // Вертеброневрология. 2004. Т. 11. № 3-4. С. 11-12; Ермакова Л.А., Шамуров Ю.С., Свиридова Л.П., Василенко А.Ф. Динамика состояния высших психических функций у больных с острыми нарушениями мозгового кровообращения разной этиологии в
}

резко смещен на изучение когнитивных и эмоциональных процессов у больных, перенесших инсульт. В то же время достоверных данных о картине поведенческих реакций и их взаимосвязи с личностью у таких больных еще не достаточно.

Теме проактивного поведения за рубежом посвящено большое число работ, причем исследования этой области представлены преимущественно в организационной психологии, психологии труда и общей психологии ${ }^{2}$. Для клинической психологии и психиатрии феномен проактивности до сих пор является относительно новым, хотя теоретические предпосылки изучения данного психоло-

левой гемисфере // Вестник Южно-Уральского государственного университета. Серия: Психология. 2009. № 5 (138). С. 25-30.

2 Baron, R.M., \& Kenny, D.A. (1986). The moderator-mediator variable distinction in social psychological research: Conceptual, strategic, and statistical considerations. Journal of Personality and Social Psychology, 51(6), 1173-1182; Bateman, T.S., \& Crant, M.J. (1993). The proactive component of organizational behavior. Journal of Organizational Behavior, 14(2), 103-118; Campbell, D.J. (2000). The proactive employee: Managing workplace initiative. Academy of Management Executive, 14, 52-66. 


\section{Психология и психотехника 9(60) • 2013}

гического явления стали намечаться еще в середине прошлого столетия, главным образом, в работах В. Франкла ${ }^{3}$ и Г. Олпорта ${ }^{4}$. Под проактивностью понимается поведение, возникающее и реализующееся преимущественно под влиянием внутренних побуждений личности (ценностных ориентаций, убеждений, установок, принципов). Проактивность противопоставляется реактивности, под которой подразумевается способность человека лишь отвечать на воздействия извне, а не формировать самостоятельно и осознанно свои поведенческие паттерны. «Реактивный», редукционистский подход представлен в основном в рамках поведенческой психологии (Дж. Уотсон, Э. Торндайк, Б. Скиннер, А. Бандура и мн. др.), этологии (К. Лоренц, Н. Тинберген, Р. Докинз, Д. Моррис и др.), а также рефлексологии (И.П. Павлов, В.М. Бехтерев, И.М. Сеченов, Б.Г. Ананьев и др.) и отчасти концепции функциональных систем (П.К. Анохин, Н.А. Бернштейн).

Итак, в клинической психологии фактически отсутствуют систематизированные данные о функционировании феномена проактивности, причем в отечественной психологической науке до сих пор нет признанной системы критериев, с помощью которых можно было бы описать проактивное поведение личности ${ }^{5}$.

ОНМК, представляя собой мультидисциплинарную проблему ${ }^{6}$, зачастую имеет тяжелые последствия для больного, что закономерно отражается на его функционировании в повседневной жизни. Инсульты довольно часто приводят к двигательным нарушениям, что также негативно влияет на поведенческую активность индивида. Часто, затрагивая когнитивную основу поведения, ОНМК приводит к снижению процессов целеполагания и планирования, что выражается также и в снижении общего уровня активности и способности критически оценивать свои поступки.

Проактивность включает в себя не только процессы программирования и контроля над осуществлением целенаправленной деятельности. Проактивное поведение - это всегда осознанное поведение с учетом возможных последствий как для самого больного, так и для его социального окружения. Важным аспектом проактивности, кроме того, выступает спонтанность, самопроизвольность, то есть способность человека

3 Франкл В. Человек в поисках смысла. М.: Прогресс, 1990.

4 Олпорт Г. Становление личности. М.: Смысл, 2002.

5 Ерзин А.И. Проактивное поведение при некоторых психических заболеваниях: критерии, факторы формирования, типология // Психиатрия, психотерапия и клиническая психология. 2012. № 4 (10). С. 64-77.

6 Антипова Л.Н., Артемьева О.В. Медико-социальная работа в первичном сосудистом отделении для больных с острым нарушением мозгового кровообращения (первый опыт) // Вестник МУЗ ГБ № 2. 2011. № 15. С. 67-75. поступать под влиянием внутренних побуждений. В связи с тем, что регулирование поведенческой активности и критическое отношение к себе у таких больных нередко становятся нарушенными, предполагается, что это прямо отражается и на спонтанности (чем ниже самоконтроль, тем выше спонтанность).

Еще одна сторона проактивного поведения - это мировоззренческая основа личности. Предполагается, что в наиболее тяжелых случаях при ОНМК последствия заболевания для больного складываются таким образом, что при отсутствии должного лечения и медико-социальной реабилитации в последующем наблюдается разрушение морально-нравственного ядра личности. Это приводит к тому, что подобные пациенты совершают неприемлемые в обществе поступки и действия.

\section{Материаль и методь}

Было обследовано 30 пациентов с ОНМК по ишемическому типу, находящихся на лечении в МБУЗ «Клиническая больница восстановительного лечения», г. Оренбург, Россия. Возраст обследованных - 35-60 лет

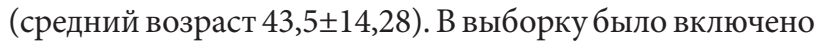
$53 \%$ женщин и $47 \%$ мужчин. Длительность нахождения в стационаре после перенесенного инсульта - 7-28 дней. Грубых нарушений мышления и памяти не выявлено. Преобладающая симптоматика: расстройства речи, гемипарезы, нарушение моторики рук.

В процессе исследования использовались следующие методы: пилотажный опросник «Проактивное поведение», методика «Проактивное совладающее поведение» Аспинвалл, Тауберта и Шварцера в адаптации Н.Е. Водопьяновой ${ }^{7}$, а также опросник «РеактивнаяПроактивная агрессия» Рэйна (Э. Рэйн с соавт.) $)^{8}$.

Опросник «Проактивное поведение» был разработан нами для исследования структурных компонентов личности и направленности проактивного поведения. Методика включает 56 пунктов, на которые испытуемый должен дать один из пяти вариантов ответов: «Совершенно верно» (оценивается в 5 баллов), «Верно» (4 балла), «Не уверен» (3 балла), «Неверно» (2 балла) и «Совершенно неверно» (1 балл). Время выполнения теста - 15-40 минут. Опросник можно использовать

\footnotetext{
7 Водопьянова Н.Е. Психодиагностика стресса. СПб: Питер, 2009. 336 c. C. 274-282.

8 Dodge K., Loeber R., Gatzke-Kopp L., Lynam D. (2006). The Reactive-Proactive Aggression Questionnaire: Differential Correlates of Reactive and Proactive Aggression in Adolescent Boys // Aggressive Behavior. Volume 32, pages 159-171; Fung A.L., Raine A., Gao Y. (2009). Cross-Cultural Generalizability of the Reactive-Proactive Aggression Questionnaire (RPQ) // Journal of Personality Assessment, 91(5), 473-479).
} 


\section{Клиническая психология}

как в индивидуальном, так и в групповом тестировании. Методика включает следующие шкалы:

1. «Осознанность действий»;

2. «Осознание последствий поведения»;

3. «Ответственность за свою жизнь»;

4. «Спонтанность»;

5. «Свобода принятия решений»;

6. «Метапотребности»;

7. «Высший уровень личности».

Помимо прочего, опросник способен выявлять направленность проактивности человека - деструктивного или конструктивного характера.

Опросник «Проактивное совладающее поведение» был разработан Аспинвалл, Шварцером и Таубертом в 1999 г. Авторы рассматривают совладающее поведение как интеграцию аффективных, когнитивных, интенциональных и социальных факторов в определенный набор копинг-стратегий, которые дают человеку возможность не только справляться со стрессовыми ситуациями, но и способствуют продвижению к важным для личности целям 9 . Опросник состоит из 55 утверждений и содержит 6 шкал:

1. «Проактивное преодоление»;

2. «Рефлексивное преодоление»;

3. «Стратегическое планирование»;

4. «Превентивное преодоление»;

5. «Поиск инструментальной поддержки»;

6. «Поиск эмоциональной поддержки».

Проактивное преодоление - процесс целеполагания, постановка важных для личности целей, а также процесс саморегуляции по достижению этих целей, включающий когнитивную и поведенческую составляющие. Сущность проактивного преодоления заключается в усилиях по формированию общих ресурсов, которые облегчают достижение важных целей и способствуют личностному росту.

Реблексивное преодоление - представление о возможных поведенческих альтернативах путем сравнения их эффективности. Включает в себя оценку возможных стрессоров, анализ проблем и имеющихся ресурсов, генерирование предполагаемого плана действий, прогноз вероятного исхода деятельности и выбор способов ее выполнения.

Стратегическое планирование представляет собой процесс создания четко продуманного, целеориентированного плана действий, в котором наиболее масштабные цели разделяются на подцели, управление достижением которых становится более доступным.

9 Водопьянова Н.Е. Психодиагностика стресса. СПб: Питер, 2009. 336 c. С. 274-282.
Превентивное преодоление - это предвосхищение потенциальных стрессоров и подготовка действий по нейтрализации негативных последствий до того, как наступит возможное стрессовое событие. Такая неопределенность стимулирует человека использовать широкий спектр копинг-поведения (накопление денежных средств, страхование, поддержание здорового образа жизни и др.).

Поиск инструментальной поддержки - это получение информации, советов и обратной связи от непосредственного социального окружения человека в период совладания со стрессами.

Поиск эмоицинальной поддержки ориентирован на регуляцию эмоционального дистресса путем разделения чувств с другими, поиска сочувствия и общения с людьми из непосредственного социального окружения человека.

Опросник «Реактивная-Проактивная агрессия» был разработан Э. Рейном, К. Доджем, Р. Лобером, Л. ГацкеКопп и Д. Линамом для изучения различий в уровне реактивной/проактивной агрессии. Опросник содержит 23 пункта и 3 варианта ответов («Никогда» - оценивается в 0 баллов, «Иногда» - 1 балл, «Часто» - 2 балла), из которых испытуемый должен выбрать только один, наиболее верно описывающий его реальное поведение. 12 вопросов теста относятся к проактивной агрессии, $11-$ к реактивной. Методика позволяет выявить как общий уровень агрессивности обследуемого, так и получить значения отдельно по обеим шкалам (реактивная/проактивная агрессия). Реактивная агрессия здесь рассматривается как реакция защитного характера в ответ на реальную или ожидаемую угрозу, фрустрацию или провокацию ${ }^{10}$. Под проактивной агрессией в данном случае понимается намеренное поведение, регулируемое внешними подкреплениями (например, денежным вознаграждением $)^{11}$ и направленное на достижение желаемой цели.

\section{Результать}

С помощью опросника «Проактивное поведение» были выявлены следующие особенности у пациентов обследованной выборки. Общий уровень проактивности - умеренный (среднее значение 216,67 из 280 возможных).

Анализируя значения по отдельным шкалам методики, мы установили, что у больных с ОНМК на первом

10 Connor D.F., Steingard R.J., Anderson J.J., Melloni R.H. (2003). Gender differences in reactive and proactive aggression. Child Psychiatry Hum Dev 33: 279-294.

11 Dodge K.A., Coie J.D. (1987). Social-information-processing factors in reactive and proactive aggression in children's peer groups. J Pers Soc Psychol 53: 1146-1158. 


\title{
Психология и психотехника 9(60) • 2013
}

\section{Результаты тестирования больных с ОНМК, полученные с помощью опросника «Проактивное поведение».}

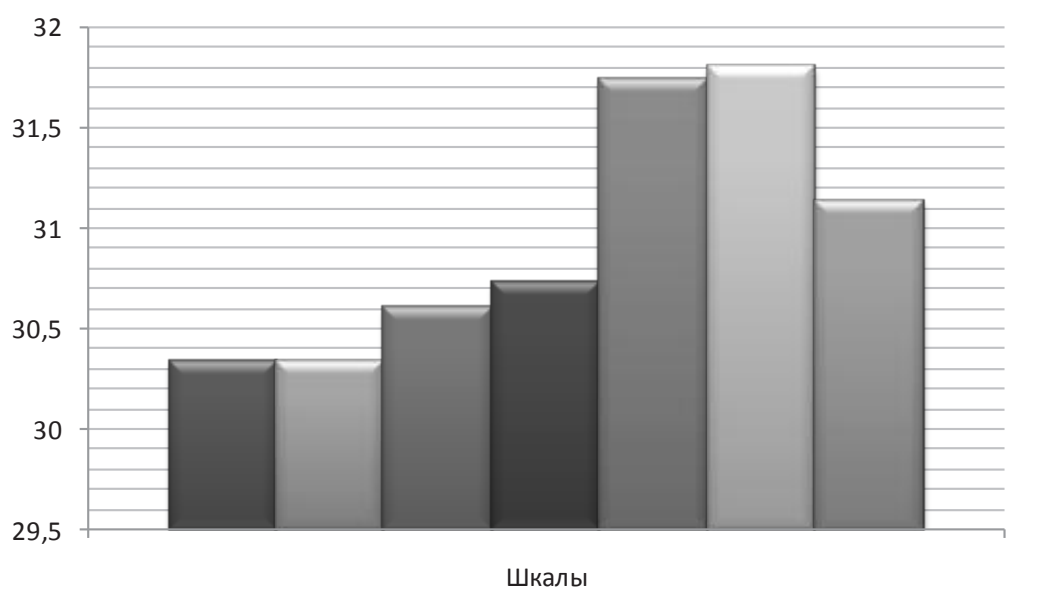

\author{
осознанность действий \\ $\square$ оосознание последствий поведения \\ ответственность за свою жизнь \\ спонтанность \\ वвобода принятия решений \\ $\square$ метапотребности \\ высший уровень личности
}

месте по частоте встречаемости оказалась шкала «Метапотребности» $(31,8)$ (рис. 1$)$, что подразумевает преобладание у испытуемых высших человеческий потребностей (метапотребностей, согласно А. Маслоу) над дефицитарными физиологическими потребностями. Данная особенность, вполне возможно, детерминирована достаточно высоким уровнем сохранности морально-нравственного ядра личности обследованных пациентов.

На втором месте по частоте встречаемости у больных с ОНМК оказалась шкала «Свобода принятия решений» $(31,73)$. Данный показатель означает, что в повседневной жизни обследованные пациенты, как правило, свободны и независимы в выборе способов и стилей поведения или считают себя таковыми. Обычно такие люди в ходе принятия решения не ориентируются на мнения и советы окружающих, а самостоятельно делают выбор.

На третьем месте оказалась шкала «Высший уровень личности» $(31,13)$, что подразумевает ориентацию при выборе моделей поведения преимущественно на собственные ценности и убеждения больных, нежели на внешние обстоятельства. Высокие значения по этой шкале также могут свидетельствовать о высокой сохранности морально-нравственной основы личности.

Четвертой по частоте встречаемости стала шкала «Спонтанность» $(30,73)$. Под спонтанностью понимается способность человека совершать поступки под влиянием внутренних мотивов, потребностей, влечений.

На пятом месте оказалась шкала «Ответственность за свою жизнь» $(30,6)$. Достаточно низкие значения по данной шкале могут свидетельствовать о безответствен- ном отношении испытуемых к своей жизни, своему здоровью, событиям, происходящим с ними.

На последнем месте расположились две взаимосвязанные шкалы - «Осознанность действий» $(30,3)$ и «Осознание последствий поведения» $(30,3)$. Низкие значения по данным шкалам демонстрируют достаточно низкую оценку испытуемыми своей способности осознанно регулировать собственное поведение. Также выявленная особенность, скорее всего, свидетельствует о некотором снижении когнитивных процессов, что закономерно проистекает из тяжелых последствий перенесенного инсульта. Способность личности критически оценивать последствия своего поведения является важной составляющей проактивности, причем у больных с ОНМК, как показало исследование, этот показатель находится на относительно низком уровне.

Достоверных различий в направленности проактивного поведения у больных с ОНМК не выявлено. Конструктивная $(27,06)$ и деструктивная $(26,8)$ проактивность выражена у обследованных в равной мере. Это означает, что как в личности испытуемых, так и в их поведении в одинаковой степени могут проявляться как конструктивные, так и деструктивные тенденции и свойства.

Результаты исследования проактивного копинг-поведения представлены на рис. 2. Так, было установлено, что доминирующим типом совладающего поведения оказалось проактивное преодоление $(27,73, \sigma=5,48)$. Это свидетельствует о том, что большинство обследованных пациентов стремится ставить перед собой личностно-значимые цели, причем нередко, как показала нарративная беседа, эти цели напрямую связаны с процессом лечения и с успешным восстановлением 


\section{Клиническая психология}

\section{Результаты, полученные с помощью опросника «Проактивное совладающее поведение»}

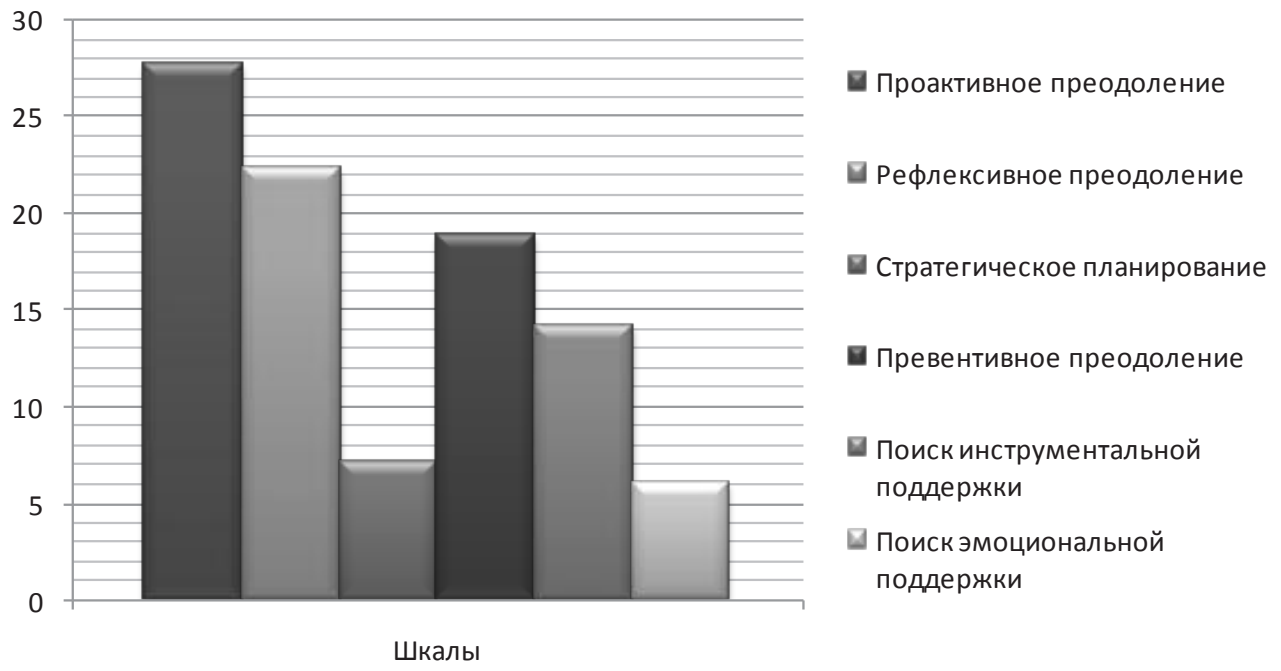

психических и двигательных функций после перенесенного инсульта. В частности, было установлено, что у лиц, активно использующих этот проактивный копинг, более эффективно и быстро восстанавливаются нарушенные высшие психические процессы, а также двигательная сфера.

На втором месте по частоте встречаемости оказалось рефлексивное преодоление $(22,33, \sigma=7,64)$. Этот тип проактивного копинг-поведения связан с оценкой потенциальных стрессоров, с анализом проблем и имеющихся ресурсов личности.

На третьем месте расположилась шкала «Превентивное преодоление» $(18,93, \sigma=4,41)$. Это может свидетельствовать о том, что больные с ОНМК склонны к предвосхищению возможных стрессовых ситуаций. Пожалуй, самой мощной и тяжелой для личности кризисной ситуацией выступает сам факт инсульта, а также вероятность получения инвалидности. Подобное обстоятельство стимулирует и мотивирует исследуемых больных к предотвращению повторения этой стрессовой ситуации в будущем, что нередко выражается в таких формах и способах поведения, как страхование собственной жизни, использование мер по укреплению и поддержанию физического здоровья и т.д.

На четвертом месте по частоте встречаемости в обследованной выборке - поиск инструментальной поддержки $(14,2, \sigma=3,49)$. Он выражается в стремлении больных получать информацию (в частности, о своем заболевании, о его последствиях, а также о возможных путях лечения и реабилитации) непосредственно от близкого социального окружения. Социальное окружение может включать как родственников больного, так и медицинский персонал клиники.

Менее всего представлены в обследованной группе больных с ОНМК стратегическое планирование $(7,06)$ и поиск эмоциональной поддержки $(6,07)$. Как было установлено, больные редко прибегают к созданию четко продуманного, целеориентированного плана дальнейших действий, а также к поиску сочувствия и общению с близкими людьми. В ходе нарративной беседы было выявлено, что больные с ОНМК, не смотря на потребность в сочувствии и сопереживании со стороны близких, реже стремятся получить эмоциональную поддержку, поскольку, как утверждало большинство опрошенных пациентов, жалость и сочувствие вовсе не придают им больше сил и энергии для борьбы с последствиями заболевания, а скорее, наоборот - заставляют их вновь и вновь думать о своей болезни, создавая условия для актуализации пережитой психотравмирующей ситуации.

Исследование форм агрессивного поведения у больных с ОНКМ показало, что ведущей формой оказалась реактивная агрессия (рис. 3). Для испытуемых более характерна ответная реакция на внешние провоцирующие факторы, выражающаяся в раздражительности, вспыльчивости и гневе, то есть в поведении, носящем импульсивный характер. Проактивная агрессия, представляя собой неспровоцированное намеренное жестокое поведение, в исследуемой выборке проявляется значительно реже, чем реактивная агрессия. 


\section{Психология и психотехника 9(60) • 2013}

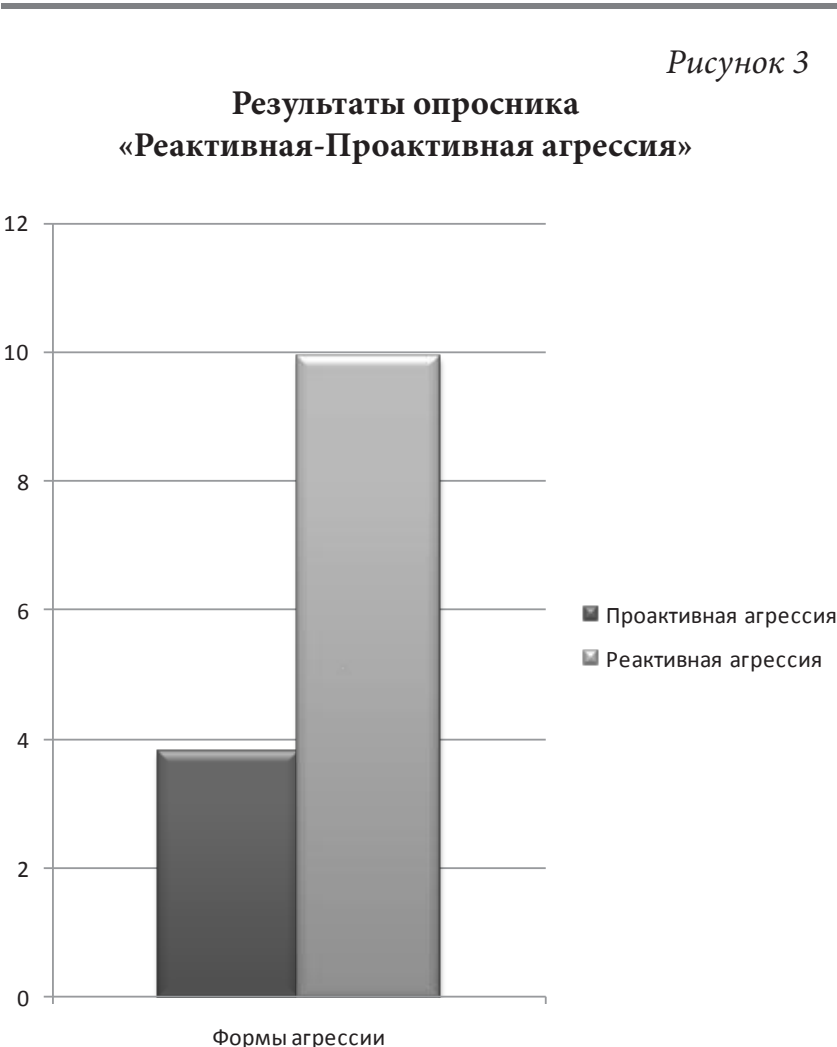

Формы агрессии

\section{Bbıодыbl}

В ходе исследования были выявлены некоторые личностные особенности проактивного поведения у больных с ОНМК по ишемическому типу, находящихся на восстановительном лечении. Исследование показало, что ведущими личностными факторами, ответственными за формирование и реализацию проактивных моделей поведения, у обследованных пациентов являются метапотребности и свобода принятия решений. Наименее развитыми компонентами проактивности у данных больных выступают осознанность действий и последствий своего поведения, что может быть обусловлено снижением когнитивных процессов, регулирующих поведенческую активность. Выраженных различий в уровне конструктивного и деструктивного проактивного поведения выявлено не было.

Анализируя формы проактивного коипнг-поведения, мы установили, что наиболее часто в обследованной группе пациентов встречаются проактивное, рефлексивное и превентивное преодоление. Использование проактивного преодоления в качестве копингстратегии заключается в постановке личностно-значимых целей, зачастую связанных с желанием больных восстановить нарушенные у них психические и дви- гательные функции. Было обнаружено, что пациенты с ОНМК, чаще прибегающие к использованию этого копинга, более эффективно проходят реабилитационный процесс, у них улучшается функционирование психических процессов и двигательного аппарата. Рефлексивное и превентивное преодоление связано с прогнозом нежелательных стрессовых ситуаций, с анализом возможных вариантов исхода событий. В ходе нарративной беседы с больными было установлено, что пациенты в большинстве случаев стремятся избежать повторения инсульта, что приводит их к использованию различных мер по поддержанию и укреплению своего здоровья.

Также было обнаружено, что для больных с ОНМК характерна реактивная агрессия, проявляющаяся в виде ответной реакции на провоцирующие стимулы. К последним следует отнести неудобства, связанные с пребыванием в стационаре, поведение близкого социального окружения, информационное воздействие и пр. Реактивная форма агрессии очень часто выражается в раздражительности и гневе, причиной которых служат внешние факторы. Проактивная агрессия как неспровоцированное намеренное жестокое поведение у обследованных пациентов проявляется значительно реже. В ходе опроса было установлено, что данная форма деструктивного поведения часто связана с убеждениями, ценностными ориентациями, желаниями и потребностями самих больных, нежели с провоцирующими стимулами.

Выявленные особенности, безусловно, играют важную роль в процессе лечения и реабилитации больных с ОНМК. Как было установлено, проактивные структурные задатки личности, проявляющие в стремлении больных к достижению значимых целей, положительно влияют на успешность и эффективность восстановительного лечения последствий ишемического инсульта. Анализ потенциальных стрессоров зачастую стимулирует пациентов прибегать к мерам по укреплению и поддержанию собственного физического здоровья, что также позитивно отражается на динамике лечения. Таким образом, важнейшую роль в процессе восстановления после инсульта играют не только методы и средства восстановительной терапии, но и проактивные личностные ресурсы самих больных, включая такие качества, как упорство, стрессоустойчивость, надежда и вера в собственные силы ${ }^{12}$.

12 Kahana E., Kahana B., Zhang J. Motivational Antecedents of Preventive Proactivity in Late Life: Linking Future Orientation and Exercise // Motivation and Emotion, Vol. 29, No. 4, December 20; Seligman, M.E., \& Csikszentmihalyi, M. (2000). Positive psychology. American Psychologist, 55 (1), 5-14. 


\section{Клиническая психология}

\section{Список литературь:}

1. Антипова Л.Н., Артемьева О.В. Медико-социальная работа в первичном сосудистом отделении для больных с острым нарушением мозгового кровообращения (первый опыт) // Вестник МУЗ ГБ № 2. 2011. № 15. C. 67-75.

2. Астаева А.В., Епанешникова Н.В. Нейропсихологическая характеристика нарушений речи при острых нарушениях мозгового кровообращения и проблемы их классификации в отечественной и зарубежной нейропсихологии // Вестник Южно-Уральского государственного университета. Серия: Психология. 2012. № 6 (265). С. 73-79.

3. Бисерова С.В., Павлова В.С. Сопоставление когнитивных и психоэмоциональных изменений у лиц, перенёсших острое нарушение мозгового кровообращения // Вятский медицинский вестник. 2007. № 1. С. 46.

4. Водопьянова Н.Е. Психодиагностика стресса. СПб: Питер, 2009. 336 с. (Серия «Практикум»).

5. Гайфутдинова Л.В., Васильева М.А. Факторы эффективности восстановления речи у больных, перенесших острое нарушение мозгового кровообращения и черепно-мозговую травму // Вертеброневрология. 2004. T. 11. № 3-4. С. 11-12.

6. Ерзин А.И. Проактивное поведение при некоторых психических заболеваниях: критерии, факторы формирования, типология // Психиатрия, психотерапия и клиническая психология. 2012. № 4 (10). С. 64-77.

7. Ерзин А.И. О проактивном совладающем поведении // NB: Психология и психотехника. 2013. № 1. С. 89-100. (URL: http://www.e-notabene.ru/psp/article_274.html).

8. Ермакова Л.А., Шамуров Ю.С., Свиридова Л.П., Василенко А.Ф. Динамика состояния высших психических функций у больных с острыми нарушениями мозгового кровообращения разной этиологии в левой гемисфере // Вестник Южно-Уральского государственного университета. Серия: Психология. 2009. № 5 (138). C. 25-30.

9. Левит Л.З. Личностно-ориентированная концепция счастья: краткая история // Психология и психотехника. 2012. № 8. С. 78-86.

10. Олпорт Г. Становление личности. М.: Смысл, 2002.

11. Франкл В. Человек в поисках смысла. М.: Прогресс, 1990.

12. Baron, R.M., \& Kenny, D.A. (1986). The moderator-mediator variable distinction in social psychological research: Conceptual, strategic, and statistical considerations. Journal of Personality and Social Psychology, 51(6), 1173-1182.

13. Bateman, T.S., \& Crant, M.J. (1993). The proactive component of organizational behavior. Journal of Organizational Behavior, 14(2), 103-118.

14. Campbell, D.J. (2000). The proactive employee: Managing workplace initiative. Academy of Management Executive, $14,52-66$

15. Connor D.F., Steingard R.J., Anderson J.J., Melloni R.H. (2003). Gender differences in reactive and proactive aggression. Child Psychiatry Hum Dev 33: 279-294.

16. Dodge K., Loeber R., Gatzke-Kopp L., Lynam D. (2006). The Reactive-Proactive Aggression Questionnaire: Differential Correlates of Reactive and Proactive Aggression in Adolescent Boys // Aggressive Behavior. Volume 32, pages 159-171.

17. Dodge K.A., Coie J.D. (1987). Social-information-processing factors in reactive and proactive aggression in children's peer groups. J Pers Soc Psychol 53: 1146-1158.

18. Fung A.L., Raine A., Gao Y. (2009). Cross-Cultural Generalizability of the Reactive-Proactive Aggression Questionnaire (RPQ) // Journal of Personality Assessment, 91(5), 473-479.

19. Kahana E., Kahana B., Zhang J. Motivational Antecedents of Preventive Proactivity in Late Life: Linking Future Orientation and Exercise // Motivation and Emotion. Vol. 29. № 4. December 20.

20. Seligman, M.E., \& Csikszentmihalyi, M. (2000). Positive psychology. American Psychologist, 55 (1), 5-14.

\section{References (transliteration):}

1. Antipova L.N., Artem'eva O.V. Mediko-social'naya rabota v pervichnom sosudistom otdelenii dlya bol'nyh s ostrym narusheniem mozgovogo krovoobrascheniya (pervyy opyt) // Vestnik MUZ GB № 2. 2011. № 15. S. 67-75. 


\section{Психология и психотехника 9(60) • 2013}

2. Astaeva A.V., Epaneshnikova N.V. Neyropsihologicheskaya harakteristika narusheniy rechi pri ostryh narusheniyah mozgovogo krovoobrascheniya i problemy ih klassifikacii v otechestvennoy i zarubezhnoy neyropsihologii // Vestnik Yuzhno-Ural'skogo gosudarstvennogo universiteta. Seriya: Psihologiya. 2012. № 6 (265). S. 73-79.

3. Biserova S.V., Pavlova B.C. Sopostavlenie kognitivnyh i psihoemocional'nyh izmeneniy u lic, perenesshih ostroe narushenie mozgovogo krovoobrascheniya // Vyatskiy medicinskiy vestnik. 2007. № 1. S. 46.

4. Vodop'yanova N.E. Psihodiagnostika stressa. SPb.: Piter, 2009. 336 s. (Seriya «Praktikum»).

5. Gayfutdinova L.V., Vasil'eva M.A. Faktory effektivnosti vosstanovleniya rechi u bol'nyh, perenesshih ostroe narushenie mozgovogo krovoobrascheniya i cherepno-mozgovuyu travmu // Vertebronevrologiya. 2004. T. 11. № 3-4. S. 11-12.

6. Erzin A.I. Proaktivnoe povedenie pri nekotoryh psihicheskih zabolevaniyah: kriterii, faktory formirovaniya, tipologiya // Psihiatriya, psihoterapiya i klinicheskaya psihologiya. 2012. № 4 (10). S. 64-77.

7. Erzin A.I. O proaktivnom sovladayuschem povedenii // NB: Psihologiya i psihotehnika. 2013. № 1. C. 89-100. (URL: http://www.e-notabene.ru/psp/article_274.html).

8. Ermakova L.A., Shamurov Yu.S., Sviridova L.P., Vasilenko A.F. Dinamika sostoyaniya vysshih psihicheskih funkciy u bol'nyh s ostrymi narusheniyami mozgovogo krovoobrascheniya raznoy etiologii v levoy gemisfere // Vestnik YuzhnoUral’skogo gosudarstvennogo universiteta. Seriya: Psihologiya. 2009. № 5 (138). S. 25-30.

9. Levit L.Z. Lichnostno-orientirovannaya koncepciya schast'ya: kratkaya istoriya // Psihologiya i psihotehnika. 2012. № 8. C. 78-86.

10. Olport G. Stanovlenie lichnosti. M.: Smysl, 2002.

11. Frankl V. Chelovek v poiskah smysla. M.: Progress, 1990.

12. Baron, R.M., \& Kenny, D.A. (1986). The moderator-mediator variable distinction in social psychological research: Conceptual, strategic, and statistical considerations. Journal of Personality and Social Psychology, 51(6), 1173-1182.

13. Bateman, T.S., \& Crant, M.J. (1993). The proactive component of organizational behavior. Journal of Organizational Behavior, 14(2), 103-118.

14. Campbell, D.J. (2000). The proactive employee: Managing workplace initiative. Academy of Management Executive, $14,52-66$

15. Connor D.F., Steingard R.J., Anderson J.J., Melloni R.H. (2003). Gender differences in reactive and proactive aggression. Child Psychiatry Hum Dev 33: 279-294.

16. Dodge K., Loeber R., Gatzke-Kopp L., Lynam D. (2006). The Reactive-Proactive Aggression Questionnaire: Differential Correlates of Reactive and Proactive Aggression in Adolescent Boys // Aggressive Behavior. Volume 32, pages 159-171.

17. Dodge K.A., Coie J.D. (1987). Social-information-processing factors in reactive and proactive aggression in children's peer groups. J Pers Soc Psychol 53: 1146-1158.

18. Fung A.L., Raine A., Gao Y. (2009). Cross-Cultural Generalizability of the Reactive-Proactive Aggression Questionnaire (RPQ) // Journal of Personality Assessment, 91(5), 473-479.

19. Kahana E., Kahana B., Zhang J. Motivational Antecedents of Preventive Proactivity in Late Life: Linking Future Orientation and Exercise // Motivation and Emotion. Vol. 29. № 4. December 20.

20. Seligman, M.E., \& Csikszentmihalyi, M. (2000). Positive psychology. American Psychologist, 55 (1), 5-14. 